\title{
Measuring dispositional forgiveness among Spanish adolescents and emerging adults: Psychometric properties of the Spanish Forgivingness Questionnaire (FQ)
}

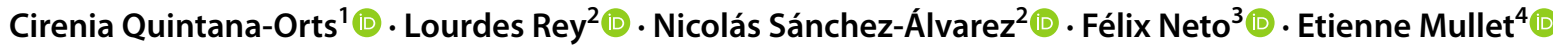

Accepted: 10 January 2022

(c) The Author(s) 2022

\begin{abstract}
The adaptation of the Forgivingness Questionnaire (FQ) has been performed for different languages and with diverse samples. So far, no psychometric properties were evaluated for a Spanish version of the FQ. The main aim of the current study was to examine the psychometric properties of the FQ in two Spanish samples: adolescents and emerging adults. A total of 1,076 participants: 419 adolescents ( $56 \%$ females; $\mathrm{M}_{\text {age }}=13.78$ years) and 657 emerging adults ( $64 \%$ females; $\mathrm{M}_{\text {age }}=21.06$ years) completed the Spanish version of FQ and other measures. The results of confirmatory factor analysis indicated a good fit for the three-factor model of the FQ, and high reliability for both samples. Convergent validity was supported and multi-group analyses showed the invariance of the factor structure of FQ across gender. These results provide evidence of good psychometric properties of the FQ as a tool to measure dispositional forgiveness among Spanish adolescents and emerging adults.
\end{abstract}

Keywords Forgivingness $\cdot$ Dispositional forgiveness $\cdot$ Spanish validation $\cdot$ Assessment $\cdot$ Adolescence $\cdot$ Emerging adulthood

Forgiveness has become a frequent theme of research in the past two decades (Worthington \& Wade, 2020). From the individual to the international levels, persons' relationships with other people are widely established by their proneness to forgive the individuals or groups who have intentionally or unintentionally harmed them. Willingness to forgive may have relevant impacts on the attitudes about family (e.g., family violence), organisations (e.g., justice system), and international occurrences (e.g., truth commissions) (e.g., Ghobari et al., 2020; Neto et al., 2011; Worthington \& Wade, 2020).

Forgiveness is the 'forswearing of negative and judgment by viewing the wrongdoer with compassion and love, in the face of a wrongdoer's considerable injustice' (Enright \& Human Development Study Group, 1991, p. 123). A key aspect about forgiveness is that to forgive does not include

Cirenia Quintana-Orts

cquintana@us.es

1 Faculty of Psychology, University of Seville, Seville, Spain

2 Faculty of Psychology, University of Malaga, Malaga, Spain

3 Faculty of Psychology and Education Sciences, University of Porto, Porto, Portugal

4 Ecole Pratique Des Hautes Etudes, Paris, France pardoning, condoning, excusing, justifying, or reconciling (Worthington \& Wade, 2020). Forgiveness should be carefully differentiated from forgivingness. Forgivingness is "the disposition to abort one's anger (or altogether to miss getting angry) at persons one takes to have wronged one culpably, by seeing them in the benevolent terms provided by reasons characteristic of forgiving" (Roberts, 1995, p. 290). Thus, in other words, forgivingness is the disposition to forgive in general, that is, applied to most circumstances in life, while forgiveness only applies to specific circumstances (e.g., a specific offense) (Worthington et al., 2015).

Taken together, forgiveness is a multifaceted construct that includes emotional, cognitive, behavioural, decisional and motivational aspects (McCullough et al., 2006). As a result of its complexity, many measures have been developed to assess several types and aspects of forgiveness, such as Heartland Forgiveness Scale (HFS); Enright Forgiveness Inventory (EFI); Transgression-Related Interpersonal Motivations inventory (TRIM-18), among many others (for a review see: Fernández-Capo et al., 2017a). They have targeted three levels of measurement specificity: (1) forgiveness of a specific offense and transgressor; (2) relationship-specific forgiveness across offenses by the same transgressor; and (3) trait forgivingness as a disposition across offenses and transgressors (Worthington et al., 
2015). One of the most commonly used instruments is the Forgivingness Questionnaire (FQ; Mullet et al., 2003). This questionnaire was developed to assess forgivingness in diverse cultural contexts, for instance, France, Indonesia, Italy, Iran, Cape Verde, Angola, or Portugal, among others (see, e.g., Barcaccia et al., 2018; Bugay \& Mullet, 2013; Nateghian et al., 2009; Neto \& Pinto, 2010; Suwartono et al., 2007; Wilks et al., 2015). It was grounded on general agreement about the process of dispositional forgiveness (Wade \& Worthington, 2003).

Mullet et al., 1998 (see also Mullet et al., 2003), using factorial techniques, evidenced a ternary structure of forgiveness. They showed that individual distinctions about the intensity of resentment were enough substantial to support the identification of a factor labelled Lasting Resentment. This aspect expresses the initial stress reaction to a transgression and the tendency to possess negative emotions, negative cognitions, and displaying avoidance behaviours in relation to offenders, even when positive circumstances are present (e.g., 'As far as I am concerned, I stay/remain resentful even if the offender has begged for forgiveness'). This aspect is evocative of the concept of unforgiveness proposed by Worthington and Wade (1999). It is usually more highly related to sociodemographic characteristics and personality (Neto \& Mullet, 2004). The individual differentiations regarding sensitivity to personal and circumstances were enough relevant to support the identification of another factor labelled Sensitivity to Circumstances. This factor exhibits the ability to examine the pros and cons of pernicious situations and to rely upon the diverse circumstances of these situations in determining whether to forgive or not forgive (e.g., 'As far as I am concerned, I more easily forgive a member of my family than anyone else'). This aspect, for example, comes linked to religious background (Mullet \& Azar, 2009). Finally, the third factor was labelled Unconditional Forgiveness. This factor denotes the tendency to cover positive attitudes in relation to the offender even when positive circumstances are not present (e.g., 'As far as I am concerned, I can easily forgive, even if the offender has not begged for forgiveness'). This aspect is highly evocative of the concept of dissipation suggested by Caprara (1986). It can be regarded as relatively independent of external influences, and the Kantian component that allows forgiving even in desperate contexts.

This psychological tripartite structure of forgivingness has also emerged in non-western cultures: in Congo (Kadima Kadiangandu et al., 2001), Lebanon (Azar \& Mullet, 2002), Macao (Paz et al., 2007), Indonesia (Suwartono et al., 2007), Iran (Nateghian et al., 2009), Angola (Neto \& Pinto, 2010), Turkey (Bugay \& Mullet, 2013), and Cape Verde (Wilks et al., 2015). The psychological structure of forgivingness seems to be similar among the diverse samples. The mean scores on lasting resentment were usually low although they varied across samples. For instance, when African samples were considered, resentment scores were slightly lower than those of comparable samples of western Europeans and Middle-Easterners. Sensitivity to Circumstances was frequently found, and scores were always higher than resentment scores. Finally, Unconditional Forgiveness was frequently found, and scores were intermediate between resentment and sensitivity scores, and were higher among Africans than among Middle-Easterners and among Westerners.

Several studies have demonstrated a significant relationship between forgiveness and well-being and emotional functioning in different age groups. For instance, a higher disposition to forgive is associated with greater satisfaction with life and lower suicidal ideation (e.g., Quintana-Orts \& Rey, 2018; Webb \& Toussaint, 2020; Yao et al., 2017), higher emotional intelligence (Wilks et al., 2015), lower revenge and avoidance motivations (e.g., Barcaccia et al., 2018, 2021). By contrast, lasting resentment is negatively linked to satisfaction with life (e.g., Sastre et al., 2003) and positively related to avoidance and revenge motivations (Barcaccia et al., 2018, 2021; Wade \& Worthington, 2003). Thus, previous research usually indicates that FQ measure has a good convergent validity as it correlates with other well-known constructs.

\section{The Present Study}

As was mentioned above, the translation and adaptation of the FQ has been performed to different languages and socio-cultural contexts. So far, there has been no translated Spanish version of the FQ. In Spanish context, there are scarce scales measuring dispositional forgiveness and allowing cross-cultural comparison (Fernández-Capo et al., 2017a). In addition, given that adolescents seem to present differences in forgiveness compared to adults (e.g., Girard \& Mullet, 1997), there is a need for available scales allowing age-related sample comparisons. Therefore, we attempted to explore the basic psychometric properties of the Spanish version of FQ with two age samples. Specifically, this study presents three main objectives. Firstly, to examine whether the factor structure found in other versions of the FQ would replicate for the Spanish version in adolescents and emerging adults. We expected the three-factor structure of the FQ would be repeatable in both Spanish samples through the Confirmatory Factorial Analysis (CFA). Secondly, to investigate factorial invariance to explore the gender- and age-related differences in the instrument's structure. We hypothesised FQ measurement invariance would hold across gender and age groups. Thirdly, to verify the relationship of FQ with other related constructs (e.g., emotional functioning and mental health factors) to add evidence of 
convergent validity. We expected to find relationships in line with existing literature (e.g., Barcaccia et al., 2021; Webb \& Toussaint, 2020; Wilks et al., 2015) in order to test the convergent validity.

\section{Method}

\section{Participants}

A normative sample took part in this study, given that the FQ measure was designed for use in general population samples (Girard \& Mullet, 1997). The sample size was calculated using G* Power. In line with Tabachnick and Fidell (2013), the sample size was calculated using the desired power and alpha level using Green's (1991) rule of thumb. The use of $\mathrm{G}^{*}$ Power was applied with the following parameters to establish a sample size: $95 \%$ Confidence level $\pm 5 \%$ error rate. The result indicated that 410 participants were needed to detect a small effect $(r=0.10)$ with a power of 0.95 and a significance level of 0.05 with a two-tailed test (Faul et al., 2009). Based on these parameters, the study samples were originally 433 adolescents and 659 emerging adults (total $\mathrm{N}=1,092$ ). Of these initial samples, 14 adolescents and 2 emerging adults did not complete some or many of the questionnaires and were excluded.

The final total sample comprised 1,076 participants (618 women), composed of the two different samples: adolescents $(\mathrm{N}=419 ; 56 \%$ females and mean age $=13.78$ years, $\mathrm{SD}=1.27)$ and emerging adults $(\mathrm{N}=657 ; 64 \%$ females and mean age $=21.06, \mathrm{SD}=1.96$ ). To control potential differences due to the size of the group samples, sensitivity power analyses were performed using $\mathrm{G}^{*}$ Power. The results of the gender (618 females and 457 males) and age (419 adolescents and 657 emerging adults) groups showed relatively low effect size $(\mathrm{d}=0.22)$ due to differences in sample sizes.

Most of the participants were Spanish (95.2\% of adolescents; $97.6 \%$ of adults). The rest of the non-Spanish adolescents who participated in the study had a fluent understanding of the Spanish language. Adolescents came from two high schools in central Spain attending between the first year and the fourth of compulsory secondary education. Emerging adults were undergraduate or master's degree students from the University of Malaga and the National Distance Education University (UNED).

\section{Instruments}

The Forgivingness Questionnaire (FQ; Mullet et al., 2003): This scale comprises 17 items expressing willingness to forgive under various conditions: five items for Lasting Resentment, seven items for Sensitivity to Circumstances, and five items for Willingness to Forgive. All items are rated on a seven-point Likert-type response scale $(1=$ completely disagree to $7=$ completely agree $)$. The FQ was translated into Spanish (see the appendix) using the back translation method.

Transgression-related interpersonal motivations scale (TRIM; McCullough et al., 2006; Spanish version by Fernández-Capo et al., 2017b). This scale comprises a seven-item TRIM-Avoidance subscale and a five-item TRIM-Revenge subscale measuring the degree to which the offended party intends to reduce contact with the transgressor and to seek revenge on the transgressor, respectively. All items are rated on a five-point Likerttype response scale $(1=$ strongly disagree to $5=$ strongly agree).

The Wong and Law Emotional Intelligence Scale (Wong \& Law, 2002; Spanish version by Extremera et al., 2019): In this scale, participants indicate four aspects of emotional intelligence (i.e., self-emotion appraisal, other's emotion appraisal, use of emotion, and regulation of emotion) through 16 items with a seven-point Likert-type response scale $(1=$ totally disagree to $7=$ totally agree $)$, providing a global score for self-reported emotional intelligence.

Satisfaction with Life Scale (Diener et al., 1985; Spanish version by Atienza et al., 2003): This scale is a self-report scale including five items aimed at assessing overall satisfaction with one's life. All items are rated on a five-point Likert-type scale ( $1=$ strongly disagree to $5=$ strongly agree).

Frequency of Suicidal Ideation Inventory (FSII; Chang \& Chang, 2016; Spanish version by Sánchez-Álvarez et al., 2020): The FSII comprises five items that assesses the frequency of suicide ideation over the past year using a fivepoint Likert-type scale ( $1=$ never to $5=$ almost every day $)$. In general, higher scores on the FSII are indicative of a greater frequency of suicide ideation.

\section{Procedure}

The adolescent participant sample were recruited by an undergraduate student who distributed the battery of questionnaires. Previously, parents were informed of participation and gave their informed consent to the school. There was no parental refusal for any adolescent's participation. The emerging adult sample were recruited via an online questionnaire disseminated during lectures at university. During data collection for both samples, the objectives of the research were described, and the confidentiality and anonymity of the answers were underlined.

The study was carried out in accordance with the Ethical Committee of the University of Malaga and the Declaration of Helsinki (2013). 


\section{Data analysis}

Statistical analyses were carried out using the Statistical Package for the Social Sciences (SPSS; IBM, 2015) and Rstudio (Rosseel, 2012). For confirmatory factor analysis (CFA) and multiple group confirmatory factor analysis (MGCFA), we used the Laavaan, semPlot, polycor, and semTools packages, using the unweighted least squares mean and variance adjusted methods. Model fit was tested using $\chi^{2}$, the comparative fit index (CFI), and the root mean square error of approximation (RMSEA) index, with values of CFI above 0.90 and RMSEA below 0.08 indicating a good fit (Kline, 2015). The percentage of missing data was acceptable $(1.46 \%)$. Thus, before running the data analyses, the missing values were imputed using the imputation algorithm of expectation-maximisation (EM) (Liang \& Bentler, 2004). To examine the factorial invariance across gender and age groups and also considering together, an MG-CFA was conducted through four factorial invariance levels: configural invariance, metric factorial invariance, scalar factorial invariance, and full factorial invariance (Timmons, 2010).

\section{Results}

\section{Descriptive Statistics of the Items}

Table 1 shows the descriptive characteristics of the FQ items. A series of preliminary analyses were conducted to explore the correct distribution of items. The skewness and kurtosis for FQ items were in an acceptable range (between $-2,2$ ), showing a normal distribution of all items (Shapiro-Wilk statistic). Possible differences between gender and age groups were examined using independent samples $t$-tests. The results showed significant differences in some of the FQ item scores, with females scoring higher on item 5 compared to males. In comparison to females, males scored higher on item 7 , item 9 , item 12 , item 13 , and item 15 . In addition, the results showed significant differences between age groups, with adolescents scoring higher on item 1, item 4 , item 7 , item 8 , item 9 , item 10 , item 11 , item 12 , item 13 , and item 15 than emerging adults. Emerging adults scored significantly higher on item 5 than adolescents.

\section{Confirmatory Factor Analysis}

Following the FQ original structural factor (Mullet et al., 1998), the three first-order factors model was successful for both samples, indicating good fit indexes for adolescents $\left[\chi^{2}(84)=200.07, p<0.001 ; \mathrm{CFI}=0.93 ; \mathrm{RMSEA}=0.05\right]$ and for emerging adults $\left[\chi^{2}(84)=407.098, p<0.001 ; \mathrm{CFI}=0.91\right.$;
RMSEA $=0.07]$. The estimation of the reliability showed good internal consistency: for adolescents, the Cronbach's alpha coefficient was $\alpha=0.79$, and McDonald's omega coefficient was $\omega=0.80$; for emerging adults, Cronbach's alpha coefficient was $\alpha=0.81$, and McDonald's omega coefficient was $\omega=0.82$. Moreover, all factor loadings were significant at $p<0.001$ and varied between 0.32 and 0.94 , with a mean of 0.64 .

\section{Multiple Group Confirmatory Factor Analysis}

The multiple-group analyses are presented in Table 2 . First, the configural fit model provided the baseline value. The analysis across age groups (adolescents vs. emerging adults) showed invariance results, with the discrepancy for full invariance and possible residual differences in item 16 . Therefore, the residual variances of the observed scores that are not accounted for by the factors are equal across groups. Then, there are some differences in the level of ease to forgive when feeling bad between adolescent and emerging adults groups. Regarding invariance analysis across gender (males vs. females), only full invariance showed discrepancy, and residual differences were in items 7 and 1. Finally, the gender and age group model comparison (adolescent females vs. males vs. emerging adult females vs. males) was examined with a discrepancy in metric invariance. Partial metric invariance was achieved liberating factor loading of items 3 and 6 . This discrepancy showed that items 3 and 6 do not contribute to the latent construct at similar degree considering both gender and age groups. Also, partial scalar invariance was achieved liberating thresholds of item 7, indicating that intercepts were not equivalent in the four groups. Full invariance model was not achieved, showing residual differences for item 7 .

Therefore, similar latent structure, loadings, thresholds, and residuals can be assumed between adolescents and adults except for item 16, and between males and females except for items 7 and 1. Lastly, the gender and age group model comparison showed that an equal latent structure, loadings (except for items 3 and 6), thresholds, and residuals (except for item 7) could be assumed, allowing comparisons across gender and age groups.

\section{Convergent Validity}

Pearson's correlations between FQ (total score and subdimensions) and all the other constructs by adolescents and emerging adults are presented separately in Table 3. In support of convergent validity in both samples, the FQ scores were positive and significantly correlated with emotional 


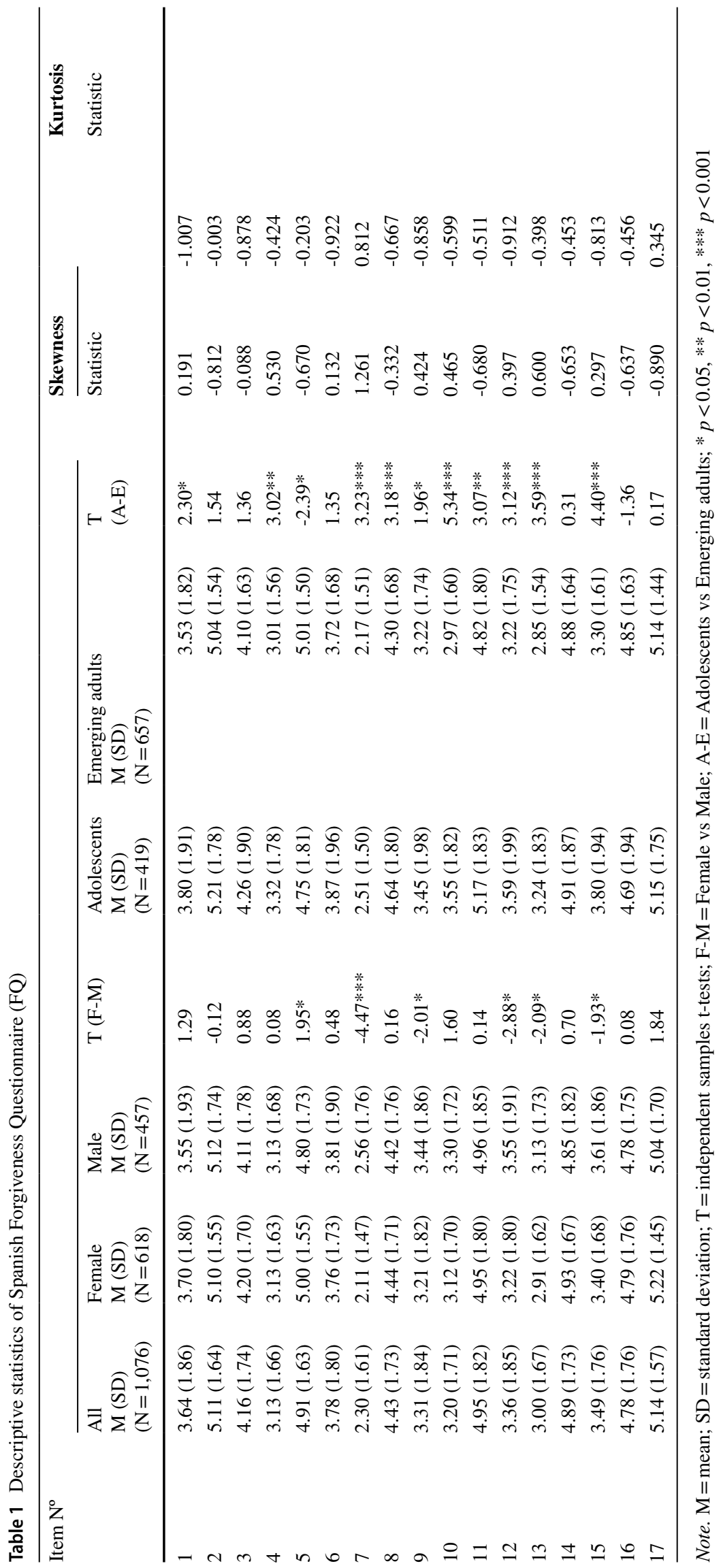


Table 2 Tests for invariance of FQ

\begin{tabular}{lccccccc}
\hline Model & $\mathrm{X}^{2}$ & $\mathrm{df}$ & CFI & RMSEA & Comparison & $\Delta$ CFI & $\Delta$ RMSEA \\
\hline Adolescents vs Emerging & adults & & & & & & \\
Model 1. Configural & 574.42 & 170 & 0.931 & 0.066 & - & - & - \\
Model 2. Metric & 646.39 & 184 & 0.921 & 0.068 & 2 vs 1 & 0.010 & 0.002 \\
Model 3. Scalar & 715.48 & 198 & 0.912 & 0.070 & 3 vs 2 & 0.009 & 0.002 \\
Model 4. Full & 1101.10 & 246 & 0.855 & 0.080 & 4 vs 3 & 0.057 & 0.010 \\
Males vs Females & & & & & & & \\
Model 1. Configural & 680.105 & 172 & 0.911 & 0.074 & - & - & - \\
Model 2. Metric & 706.13 & 186 & 0.909 & 0.072 & 2 vs 1 & 0.002 & 0.002 \\
Model 3. Scalar & 757.23 & 200 & 0.902 & 0.072 & 3 vs 2 & 0.007 & 0.000 \\
Model 4. Full & 930.92 & 247 & 0.880 & 0.072 & 4 vs 3 & 0.022 & 0.000 \\
Adolescents Females vs Males vs Emerging adults Females vs Males & & & \\
Model 1. Configural & 966.25 & 352 & 0.898 & 0.081 & - & - & - \\
Model 2. Metric & 1077.61 & 394 & 0.887 & 0.080 & 2 vs 1 & 0.011 & 0.001 \\
Model 2P. Partial Metric & 951.12 & 386 & 0.906 & 0.074 & 2P vs 1 & 0.006 & 0.007 \\
Model 3. Scalar & 1090.83 & 428 & 0.890 & 0.076 & 3 vs 2P & 0.016 & 0.002 \\
Model 3P. Partial Scalar & 1011.73 & 408 & 0.900 & 0.074 & 3P vs 2P & 0.006 & 0.000 \\
Model 4. Full & 1616.58 & 564 & 0.826 & 0.083 & 4 vs 3P & 0.074 & 0.009 \\
\hline
\end{tabular}

intelligence and satisfaction with life, and negatively correlated with revenge, avoidance, and suicide ideations. The internal consistency values showed appropriate reliability for all instruments, ranging from 0.71 to 0.91 .

\section{Discussion}

The present research examined the psychometric properties of the Spanish version of the Forgiveness Questionnaire (FQ) in two different samples. Firstly, the results indicated that the FQ demonstrated good psychometric properties that confirm its reliability as a measure of the willingness to forgiveness, with the expected distribution of three-factor structure (i.e., propensity to lasting resentment, sensitivity to circumstances, and willingness to forgive) and items equally distributed in each scale in emerging adults and adolescents samples. Secondly, its measurement invariance across gender and age groups was confirmed for both samples. However, it was found some discrepancies in the invariance across gender- and age- groups and differences in the correlations between factors, which mirrors previous research suggesting variations in the conceptualisation and use of forgiveness (Garthe \& Guz, 2020; Mullet et al., 2003; Silton et al., 2013). Thirdly, similarly to previous studies, the results of this study verified the convergent validity of the FQ among adolescents and emerging adults.
The measurement invariance of the FQ across age group (adolescents vs. emerging adults) was tested. Altought taken together, the FQ did assess the same structure of the different age groups, the analysis also showed invariance results, with the discrepancy for full invariance and possible residual differences in item 16. It is possible that for adolescents forgive when they are feeling bad would be more or less easily depending on the relational context factors (e.g., attitude of others, social proximity, the existence of apologies) (Mullet, 2021). Regarding the differences between emerging adult and adolescent responses in the relations between forgiveness and sensitivity to circumstances, a possible explanation could rely on the process of reasoning on forgiveness (Enright et al., 1989), grounded in cognitive and moral development. Enright and colleagues (Enright et al., 1989) found differences in how children, adolescents, and adults consider forgiveness, i.e. older subjects tend to think that forgiveness is something that is based around maintaining social relationships, as consequence of philosophical/spiritual attitudes, without interventions from friends or family, and regardless of whether restitution occurred. Based on these previous findings, Girard and Mullet (2012) also found differences in the development of the willingness to forgive among young and old adolescents (aged 11 to 18) considering seven situational factors (e.g., cancellation of consequences or the effect of the intention). 


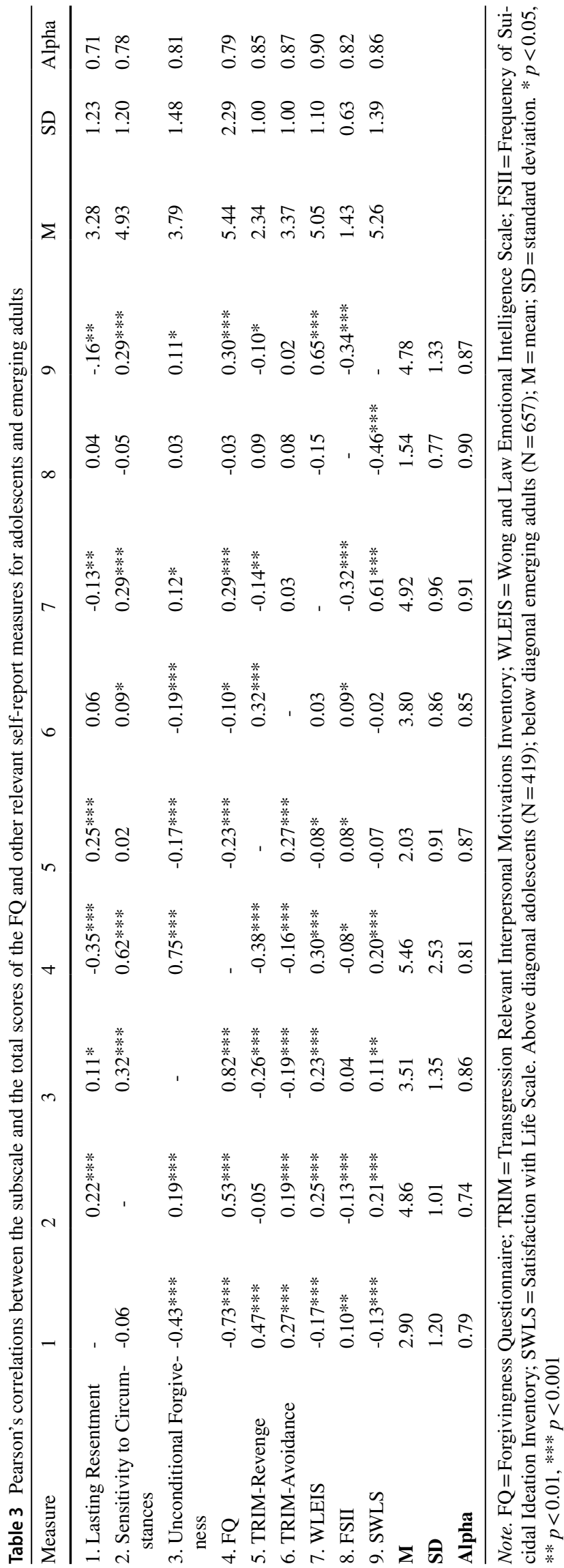

Some researchers found that adolescents were less willing to forgive compared to older age groups (Kaleta \& Mroz, 2018; Steiner et al., 2011). Based on Erickson's psychosocial developmental theory, previous results suggest that age might be related to the way people face interpersonal conflict, with adults being more prone to move from a self-centred orientation to another-centred orientation (Kaleta \& Mroz, 2018). As per Garthe and Guz (2020), the conceptualisation and use of forgiveness may develop in line with developmental processes: self-regulation, socialisation processes, and coping strategies. Children and adolescents would increasingly be able to use a greater number or regulation and coping strategies with age, simultaneous to their exposure to socialisation models and experiences (Garthe \& Guz, 2020), achieving mature selfregulation strategies at approximately the end of one's twenties (Arnett, 2015; Garnefski et al., 2002).

It is suggested that, during adolescence, where stressful and conflict situations increase, young people will develop changes and try new coping strategies more focused on problem-solving and lower on modifying the situation and avoiding (Eschenbeck et al., 2018; Zimmermann \& Iwanski, 2014). With age, adults are more able to employ complex emotional processes and be less emotionally strained due to the use of a wider variety of active and constructive strategies (e.g., Flannery et al., 2018; Zimmermann \& Iwanski, 2014). In the same vein, results have shown that, as people age, they tend to reduce their hostile emotions and resentment toward offenders in a variety of situations (Steiner et al., 2011). McCullough et al. (2003) discussed that a forgiving attitude after an interpersonal transgression is more laboured, complex, and/or time-consuming than just reducing hostility and unforgiving. So, in the case of adults, it may be that there exists an internal shift from negative emotions (i.e., resentment) to more neutral or positive emotions (i.e., empathy, respect, and compassion). By contrast, adolescents would make the choice not to retaliate or exact revenge, consisting of cognitive judgments and decisions without an emotional shift to more neutral or positive feelings towards the perpetrator.

Measurement invariance analyses regarding participant gender were performed for both samples across three different levels (i.e., configural, metric, scalar). Our results show that the measures are variant. In particular, items 1 and 7 residuals were constrained, and re-testing model showed a partially full invariant. Both items were included in lasting resentment. Also item 16, related to sensitivity to circumstances, presents differences between groups. This could be in line with previous research suggesting gender differences in the levels of 
forgiveness and unforgiveness by both men and women, with men generally being a little less forgiving and more resentful than women (e.g., Neto \& Mullet, 2004; Romero \& Mitchell, 2008). These differences may also be related to other factors such as the severity of the offense, the existence of apologies, the level of anger after the aggression, or age (Mullet, 2021). Johnson et al. (2013) found that the use of forgiveness may not differ for girls and boys, but the factors predicting this use do. Considering the items 1,7 , and 16 , our results suggest that the differences between males and females may be more related to the circumstances of harmful situations for deciding whether to forgive or not the offender such as the mood, the existence of apologies and some believes and cognitive judgments affecting resentment. Furthermore, Mullet (2021) argued that these factors may impact forgiveness as a function of age.

Besides, the gender and age group model comparison (adolescent females vs. males vs. emerging adult females vs. males) was examined with a discrepancy in metric invariance, suggesting that the scores in some items of the four particular groups (e.g., emerging adults females) are differently distributed in comparison to others groups. These differences were found in items 3 and 6, which describe the level of unconditional forgiving attitude related to the cancellation of the consequences and the severity of the offense, as well as in item 7 referring to lasting resentment. These discrepancies between groups' scores are in line with Romero and Mitchell (2008) who found differences between older and younger women, with the oldest being more forgiving. Thus, our findings highlight that, although there are not big differences regarding gender and age groups, there are some important factors underlying the level of forgiveness development and the use of forgiveness. In future research it is needed to trace the development of forgiveness considering aspects of gender socialization, as well as emotional, and cognitive development (Mullet, 2021). Taking into account the results of this study, the FQ is an instrument that may help in these first steps in the field of understanding the development of forgiveness.

Regarding the third objective, convergent validity was supported and correlations between the subscales of the FQ and other variables were consistent with earlier studies on adolescent and adult samples. Firstly, in line with previous studies for both samples, emotional intelligence and satisfaction with life correlations were found with forgivingness (Wilks et al., 2015; Yao et al., 2017) and lasting resentment (Sastre et al., 2003). In addition, negative associations were found between avoidance and revenge and forgivingness, as well as positive associations with lasting resentment (e.g., Barcaccia et al., 2018, 2021; Wade \& Worthington, 2003). Likewise, negative associations with suicidal ideation were in accordance with previous research (Quintana-Orts \& Rey, 2018; Webb \& Toussaint, 2020). These results indicated that FQ has a good convergent validity, suggesting that it is a valid instrument to assess three aspects of dispositional forgiveness in Spanish-speaking adolescents and emerging adults.

\section{Limitations and Future Studies}

Some limitations to this research and future research lines should be acknowledged. The main limitation relates to the convenience sample, which might reduce the generalisation power of our findings. The cross-sectional nature of the measurement invariance data made it impossible to indicate the effectiveness of the instrument at different times, so longitudinal data is needed to address this issue. In addition, although this study considered two age groups (i.e., adolescents and emerging adults), it did not take into account the differences in the adolescent age group. Previous research reported differences during adolescence and adulthood (e.g., Girard \& Mullet, 2012; Wainryb et al., 2020), so age-related differences and shifts in the response of forgiveness should be the focus of future studies.

Despite these limitations, the main purpose of this study was achieved, providing psychometric evidence for the FQ measure in Spanish adolescents and emerging adults, which allows us to use this instrument in further studies. Considering that, in Spain, there are relatively few measures of forgiveness, the examination of the psychometric properties of the FQ in two Spanish samples reveals some strengths and implications to Spanish research and clinical and educational contexts. For instance, our findings provide empirical support for the robustness of this measure across language groups, in this case with a sample of Spanishspeaking adolescents and emerging adults. Moreover, it will allow researchers to further develop cross-cultural work comparing FQ levels in different Spanish-speaking populations. Also, related to health and educational contexts, FQ could help professionals design appropriate therapeutic intervention and educational programs. In sum, the present study has replicated the factorial model of the original scale and provides promising and consistent evidence that the FQ is a reliable instrument to be used in the Spanish context to assess three aspects of dispositional forgiveness. 


\section{Appendix}

Table 4 Items of the Spanish version of Forgiveness Questionnaire (FQ)

1. Sigo sintiendo resentimiento incluso si la persona que me hizo daño viene a pedirme perdón [I feel unable to forgive even if the offender has begged for forgiveness]

2. Perdono más fácilmente cuando me siento de buen humor y cuando todo va bien [I can forgive more easily when I feel good]

3. Puedo perdonar fácilmente aunque las consecuencias del daño que me hicieron no hayan desaparecido [I can forgive easily even if the consequences of harm have not been canceled]

4. No me siento capaz de perdonar aunque la persona que me hizo daño se haya disculpado [I feel unable to forgive even if the offender has apologized]

5. Puedo perdonar más fácilmente cuando las consecuencias del daño que me hicieron han desaparecido [I feel it is easier to forgive once the consequences of harm have been canceled]

6. Puedo perdonar de verdad incluso cuando las consecuencias del daño que me hicieron son graves [I can truly forgive even if the consequences of harm are serious]

7. Mi forma de ver el mundo me lleva a que nunca perdone nada [The way I consider the world has brought me to never forgive]

8. Me es más fácil perdonar si mi familia o mis amigos me animan a eso [I feel it is easier to forgive when my family or my friends have invited me to do so]

9. Perdono fácilmente incluso cuando la persona que me hizo daño no me pidió perdón [I can easily forgive even when the offender has not apologized]

10. Sigo sintiendo resentimiento incluso cuando las consecuencias del daño que me hicieron son mínimas [I cannot forgive even if the consequences of the harm are minimal]

11. Me es más fácil perdonar a un miembro de mi familia que a cualquier otra persona [It is easier to forgive a member of the family than someone else]

12. Perdono fácilmente incluso cuando la persona que me hizo daño no se ha disculpado [I can easily forgive even when the offender has not apologized]

13. No me siento capaz de perdonar aunque desaparezcan las consecuencias del daño que me hicieron [I do not feel able to forgive even if the consequences of the harm have been canceled]

14. Me es más fácil perdonar a alguien que conozco bien que a alguien que no conozco [I feel it is easier to forgive somebody I know well than somebody I do not know well]

15. Puedo perdonar de verdad incluso cuando la persona que me hizo daño lo hizo de manera intencionada [I can truly forgive even if the offender did harm intentionally]

16. Me cuesta más perdonar cuando estoy de mal humor y siento que todo va mal [I forgive less easily when I feel bad]

17. Perdono más fácilmente cuando una persona que me hizo daño ha venido a pedirme perdón [I forgive more easily if the offender has begged for forgiveness]

Note. Lasting resentment: items 1, 4, 7, 10, 13; sensitivity to circumstances: items 2, 5, 8, 11, 14, 16, 17; unconditional forgiveness: items 3, 6, 9, 12,15

Acknowledgements The authors thank all participants. We acknowledge partial support from the Spanish Ministry of Science, Innovation and Universities for her Postdoctoral Research Fellowship for the Postdoctoral Research Fellowship to the first author (grant number: FJC2019038942-I/AEI/ 10.13039/501100011033) and the partial support by University of Málaga, PAIDI Group CTS-1048 (Junta de Andalucía).

Authors' Contributions C.Q.-O.: made substantial contributions to the conception and design of the work, and drafted the work.

L.R.: Design the work, collected data, and funding and supervised the work.

N.S.-A.: made substantial contributions to the analysis and interpretation of data.

F.N.: made substantial contributions to the interpretation of data and revised it critically for important intellectual content.

E.M.: revised it critically for important intellectual content.

All authors: approved the version to be published and agree to be accountable for all aspects of the work in ensuring that questions related to the accuracy or integrity of any part of the work are appropriately investigated and resolved.

Funding Open Access funding provided thanks to the CRUE-CSIC agreement with Springer Nature. The research leading to these results received partial funding from 'Juan de la Cierva-Formación' Postdoctoral Research Fellowship from the Spanish Ministry of Science, Innovation and Universities to the first author under Grant Agreement No FJC2019-038942-I/AEI/ 10.13039/501100011033 and PAIDI Group CTS-1048 (Junta de Andalucía).

Data Availability The datasets generated during and/or analysed during the current study are not publicly available due to ethical restrictions to ensure anonymity and privacy of the answers but are available from the corresponding author on reasonable request.

Code Availability Not applicable. 


\section{Declarations}

Conflict of Interest On behalf of all authors, the corresponding author states that there is no conflict of interest.

Competing Interests The authors have no relevant financial or nonfinancial interests to disclose.

Ethics Approval Approval was obtained from the ethics committee of University of Malaga (CEUMA; approval number 62/2016-H) in accordance with the ethical standards as laid down in the $2013 \mathrm{Dec}-$ laration of Helsinki, and informed consent was obtained from all the participants.

Consent to Participate Informed consent was obtained from all individual participants included in the study.

Consent for Publication Not applicable.

Open Access This article is licensed under a Creative Commons Attribution 4.0 International License, which permits use, sharing, adaptation, distribution and reproduction in any medium or format, as long as you give appropriate credit to the original author(s) and the source, provide a link to the Creative Commons licence, and indicate if changes were made. The images or other third party material in this article are included in the article's Creative Commons licence, unless indicated otherwise in a credit line to the material. If material is not included in the article's Creative Commons licence and your intended use is not permitted by statutory regulation or exceeds the permitted use, you will need to obtain permission directly from the copyright holder. To view a copy of this licence, visit http://creativecommons.org/licenses/by/4.0/.

\section{References}

Arnett, J. J. (2015). Socialization in emerging adulthood: From the family to the wider world, from socialization to self-socialization. In J. E. Grusec \& P. D. Hastings (Eds.), Handbook of socialization: Theory and research (pp. 85-346). Guildford Press.

Atienza, F. L., Balaguer, I., \& García-Merita, M. L. (2003). Satisfaction with life scale: Analysis of factorial invariance across sexes. Personality and Individual Differences, 35(6), 1255-1260. https:// doi.org/10.1016/S0191-8869(02)00332-X

Azar, F., \& Mullet, E. (2002). Forgiveness: Overall level and factor structure in a sample of Muslim and Christian-Lebanese. Peace and Conflict: A Peace Psychology Journal, 8, 17-30.

Barcaccia, B., Ioverno, S., Salvati, M., Medvedev, O. N., Pallini, S., \& Vecchio, G. M. (2021). Measuring predictors of psychopathology in Italian adolescents: Forgiveness, avoidance and revenge. Current Psychology, 1-15. https://doi.org/10.1007/s12144-021-01414-2

Barcaccia, B., Milioni, M., Pallini, S., \& Vecchio, G. M. (2018). Resentment or forgiveness? The assessment of forgivingness among Italian adolescents. Child Indicators Research, 11(4), 1407-1423. https://doi.org/10.1007/s12187-017-9483-6

Bugay, A., \& Mullet, E. (2013). Conceptualizing forgiveness, granting forgiveness, and seeking forgiveness: A Turkish-French comparison. Review of European Studies, 5, 187-193. https:// doi.org/10.5539/res.v5n5p187

Caprara, G. V. (1986). Indicators of aggression: The dissipationrumination scale. Personality and Individual Differences, 7 , 763-769. https://doi.org/10.1016/0191-8869(86)90074-7

Chang, E. C., \& Chang, O. D. (2016). Development of the Frequency ofSuicidal Ideation Inventory: Evidence for the validity and reliabilityof a brief measure of suicidal ideation frequency in a college studentpopulation. Cognitive Therapy and Research, 40(4), 549-556. https://doi.org/10.1007/s10608-016-9758-0.

Chen, F. F. (2007). Sensitivity of goodness of fit indexes to lack of measurement invariance. Structural Equation Modeling, 14(3), 464-504. https://doi.org/10.1080/10705510701301834

Diener, E., Emmons, R., Larsen, J., \& Griffin, S. (1985). The satisfaction with life scale. Journal of Personality Assessmemt, 49, 71-75. https://doi.org/10.1207/s15327752jpa4901_13

Enright, R. D. The Human Development Study Group. (1991). The moral development of forgiveness. In W. Kurtines \& J. Gewirtz (Eds.), Handbook of moral behavior and development, (pp. 123-152). Erlbaum.

Enright, R. D., Santos, M. J., \& Al-Mabuk, R. (1989). The adolescent as forgiver. Journal of Adolescence, 12(1), 95-110. https:// doi.org/10.1016/0140-1971(89)90092-4

Eschenbeck, H., Schmid, S., Schröder, I., Wasserfall, N., \& Kohlmann, C. W. (2018). Development of coping strategies from childhood to adolescence. European Journal of Health Psychology, 25, 18-30. https://doi.org/10.1027/2512-8442/a000005

Extremera, N., Rey, L., \& Sánchez-Álvarez, N. (2019). Validation of the Spanish version of the Wong Law Emotional Intelligence Scale (WLEIS-S). Psicothema, 31, 94-100. https://doi.org/10. 7334/psicothema2018.147

Faul, F., Erdfelder, E., Buchner, A., \& Lang, A. G. (2009). Statistical power analyses using $\mathrm{G}^{*}$ Power 3.1: Tests for correlation and regression analyses. Behavior research methods, 41(4), 1149-1160. https://doi.org/10.3758/BRM.41.4.1149

Fernández-Capo, M., Recoder, S., Gámiz, M., Gómez-Benito, J., \& Worthington, E. L., Jr. (2017a). Measuring forgiveness: A systematic review. European Psychologist, 22, 247-262. https:// doi.org/10.1027/1016-9040/a000303

Fernández-Capo, M., Recoder, S., Gómez-Benito, J., Gámiz, M., GualGarcía, P., Díez, P., \& Worthington, E. L., Jr. (2017b). Exploring the dimensionality and the psychometric properties of the TRIM-18 in the Spanish context. Anales De Psicología, 33(3), 548-555. https://doi.org/10.6018/analesps.33.2.264461

Flannery, K. M., Vannucci, A., \& Ohannessian, C. M. (2018). Using time-varying effect modeling to examine age-varying gender differences in coping throughout adolescence and emerging adulthood. Journal of Adolescent Health, 62(3), 27-34. https:// doi.org/10.1016/j.jadohealth.2017.09.027

Garnefski, N., Legerstee, J., Kraaij, V., van Den Kommer, T., \& Teerds, J. A. N. (2002). Cognitive coping strategies and symptoms of depression and anxiety: A comparison between adolescents and adults. Journal of Adolescence, 25(6), 603-611. https://doi.org/10.1006/jado.2002.0507

Garthe, R. C., \& Guz, S. (2020). The development of forgiving in children, adolescents, and emerging adults. In E.L.Worthington \& N.G. Wade (Eds.), Handbook of forgiveness (pp. 87-96). Routledge.

Girard, M., \& Mullet, E. (2012). Development of the forgiveness schema in adolescence. Universitas Psychologica, 11(4), 1235-1244.

Ghobari Bonab, B., Khodayarifard, M., Geshnigani, R. H., Khoei, B., Nosrati, F., Song, M. J., \& Enright, R. D. (2020). Effectiveness of forgiveness education with adolescents in reducing anger and ethnic prejudice in Iran. Journal of Educational Psychology, 113(4), 846-860. https://doi.org/10.1037/edu0000622

Girard, M., \& Mullet, E. (1997). Forgiveness in adolescents young middle-aged and older adults. Journal of Adult Development, 4(4), 209-220. https://doi.org/10.1007/BF02511412

Green, B. F. (1991). Computer-based adaptive testing in 1991. Psychology \& Marketing, 8(4), 243-257. https://doi.org/10.1002/mar. 4220080403

IBM, S. P. S. S. (2015). IBM SPSS Statistics Version 23. International Business Machines Corp., Boston.

Johnson, H. D., Wernli, M. A., \& LaVoie, J. C. (2013). Situational, interpersonal, and intrapersonal characteristic associations with 
adolescent conflict forgiveness. The Journal of Genetic Psychology, 174(3), 291-315. https://doi.org/10.1080/00221325.2012.670672

Kadiangandu, K. J., Mullet, E., \& Vinsonneau, G. (2001). Forgivingness: A Congo-France comparison. Journal of Cross-Cultural Psychology, 32, 504-511. https://doi.org/10.1177/0022022101032004009

Kaleta, K., \& Mróz, J. (2018). Forgiveness and life satisfaction across different age groups in adults. Personality and Individual Differences, 120,17-23. https://doi.org/10.1016/j.paid.2017.08.008

Kline, R. B. (2015). Principles and practice of structural equation modeling. Guilford publications.

Liang, J., \& Bentler, P. M. (2004). An EM algorithm for fitting twolevel structural equation models. Psychometrika, 69(1), 101-122. https://doi.org/10.1007/BF02295842

McCullough, M. E., Fincham, F. D., \& Tsang, J. A. (2003). Forgiveness, forbearance, and time: The temporal unfolding of transgression-related interpersonal motivations. Journal of Personality and Social Psychology, 84(3), 540-557. https://doi.org/10.1037/0022-3514.84.3.540

McCullough, M. E., Root, L. M., \& Cohen, A. D. (2006). Writing about the benefits of an interpersonal transgression facilitates forgiveness. Journal of Consulting and Clinical Psychology, 74, 887-897. https://doi.org/10.1037/0022-006X.74.5.887

Mullet, E. (2021). The development of forgiveness. In Enright, R. (Ed.), Handbook of forgiveness in philosophy and psychology. London: Routledge.

Mullet, E., \& Azar, F. (2009). Apologies, repentance and forgiveness: A Muslim-Christian comparison. The International Journal for the Psychology of Religion, 19, 275-285. https://doi.org/10.1080/ 10508610903146274

Mullet, E., Barros, J., Frongia, L., Usai, V., Neto, F., \& Shafighi, S. (2003). Religious involvement and the forgiving personality. Journal of Personality, 71(1), 1-19. https://doi.org/10.1111/14676494.t01-1-00003

Mullet, E., Houdbine, A., Laumonier, S., \& Girard, M. (1998). Forgivingness: Factorial structure in a sample of young, middle-aged, and elderly adults. European Psychologist, 3, 289-297. https:// doi.org/10.1027/1016-9040.3.4.289

Nateghian, S., Molazadeh, J., Lignon, S., \& Mullet, E. (2009). Forgivingness: An Iran-France comparison. Advances in Psychology Research, 66, 347-351.

Neto, F., \& Mullet, E. (2004). Personality, self-esteem, and self-construal as correlates of forgivingness. European Journal of Personality, 18, 15-30. https://doi.org/10.1002/per.500

Neto, F., \& Pinto, M. C. (2010). Forgivingness: An Angolan-Portuguese comparison. Journal of Psychology in Africa, 20, 275-280. https://doi.org/10.1080/14330237.2010.10820376

Neto, F., da Conceição Pinto, M., \& Mullet, E. (2011). Forgiveness and reconciliation in an intergroup context: East Timor's perspectives. Nova Science Publishers.

Paz, R., Neto, F., \& Mullet, E. (2007). Forgivingness: Similarities and differences between Buddhists and Christians living in China. The International Journal for the Psychology of Religion, 17, 289-301. https://doi.org/10.1080/10508610701572788

Quintana-Orts, C., \& Rey, L. (2018). Forgiveness, depression, and suicidal behavior in adolescents: Gender differences in this relationship. The Journal of Genetic Psychology, 179(2), 85-89. https:// doi.org/10.1080/00221325.2018.1434478

Roberts, R. C. (1995). Forgivingness. American Philosophical Quarterly, 32, 289-306.

Romero, C., \& Mitchell, D. B. (2008). Forgiveness of interpersonal offenses in younger and older roman catholic women. Journal of Adult Development, 15(2), 55-61. https://doi.org/10.1007/s10804-007-9036-1

Rosseel, Y. (2012). Lavaan: An R package for structural equation modeling. R package version $0.5-15$ http://lavaan.org. Journal of Statistical Software, 48(2), 1-36. Retrieved from https://econpapers. repec.org/article/jssjstsof/v_3a048_3ai02.htm\%0Ahttp://www. jstatsoft.org/v48/i02/
Sánchez-Álvarez, N., Extremera, N., Rey, L., Chang, E. C., \& Chang, O. D. (2020). Frequency of suicidal ideation inventory: Psychometric properties of the Spanish version. Psicothema, 32(2), 253-260. https://doi.org/10.7334/psicothema2019.344

Sastre, M. T. M., Vinsonneau, G., Neto, F., Girard, M., \& Mullet, E. (2003). Forgivingness and satisfaction with life. Journal of Happiness Studies, 4(3), 323-335. https://doi.org/10.1023/A:1026251630478

Silton, N. R., Flannelly, K. J., \& Lutjen, L. J. (2013). It pays to forgive! Aging, forgiveness, hostility, and health. Journal of Adult Development, 20(4), 222-231. https://doi.org/10.1007/s10804-013-9173-7

Steiner, M., Allemand, M., \& McCullough, M. E. (2011). Age differences in forgivingness: The role of transgression frequency and intensity. Journal of Research in Personality, 45(6), 670-678. https://doi.org/10.1016/j.jrp.2011.09.004

Suwartono, C., Prawasti, C. Y., \& Mullet, E. (2007). Effect of culture on forgivingness: A Southern-Asia-Western Europe comparison. Personality and Individual Differences, 42, 513-523. https://doi. org/10.1016/j.paid.2006.07.027

Tabachnick, B. G., \& Fidell, L. S. (2013). Using multivariate statistics (6th International Ed.). Thousand Oaks: Sage Publications.

Timmons, A. (2010). Establishing factorial invariance for multiplegroupconfirmatory factor analysis. KUant Guide, 22. Retrieved from http://crmda.dept.ku.edu/resources/kuantguides/22.Facto rial_Invariance_Guide.pdf

Wade, N. G., \& Worthington, E. L. (2003). Overcoming interpersonal offenses: Is forgiveness the only way to deal with unforgiveness? Journal of Counseling and Development, 81, 343-353. https://doi. org/10.1002/j.1556-6678.2003.tb00261.x

Wainryb, C., Recchia, H., Faulconbridge, O., \& Pasupathi, M. (2020). To err is human: Forgiveness across childhood and adolescence. Social Development, 29(2), 509-525. https://doi.org/10.1111/sode.12413

Webb, J. R., \& Toussaint, L. L. (2020). Forgiveness, Well-Being, and Mental Health. In E.L.Worthington \& N.G. Wade (Eds.), Handbook of forgiveness (pp. 188-197). Routledge.

Wilks, D. C., Neto, F., \& Mavroveli, S. (2015). Trait emotional intelligence, forgiveness, and gratitude in Cape Verdean and Portuguese students. South African Journal of Psychology, 45(1), 93-101. https://doi.org/10.1177/0081246314546347

Wong, C. S., \& Law, K. S. (2002). The effects of leader and follower emotional intelligence on performance and attitude: An exploratory study. The Leadership Quarterly, 13(3), 243-274. https://doi. org/10.1016/S1048-9843(02)00099-1

Worthington, E. L., Jr., Lavelock, C., Witvliet, C. V. O., Rye, M. S., Tsang, J.-A., \& Toussaint, L. (2015). Measures of forgiveness: Self-report, physiological, chemical, and behavioral indicators. In Greg Boyle, Don Saklofske, \& Gerald Matthews (Eds.), Measures of personality and social psychological constructs (pp. 474-504). Elsevier Academic. https://doi.org/10.1016/B978-0-12-386915-9.00017-6

Worthington, E. L., \& Wade, N. G. (Eds.). (2020). Handbook of forgiveness (2nd ed.). Routledge.

Worthington, E. L., Jr., \& Wade, N. G. (1999). The social psychology of unforgiveness and forgiveness and implications for clinical practice. Journal of Social and Clinical Psychology, 18, 385-418. https://doi.org/10.1521/jscp.1999.18.4.385

Yao, S., Chen, J., Yu, X., \& Sang, J. (2017). Mediator roles of interpersonal forgiveness and self-forgiveness between self-esteem and subjective well-being. Current Psychology, 36(3), 585-592. https://doi.org/10.1007/s12144-016-9447-x

Zimmermann, P., \& Iwanski, A. (2014). Emotion regulation from early adolescence to emerging adulthood and middle adulthood: Age differences, gender differences, and emotion-specific developmental variations. International Journal of Behavioral Development, 38(2), 182-194. https://doi.org/10.1177/0165025413515405

Publisher's Note Springer Nature remains neutral with regard to jurisdictional claims in published maps and institutional affiliations. 